\title{
Lewis-base silane activation: from reductive cleavage of aryl ethers to selective ortho-silylation $†$
}

\begin{abstract}
Alexey Fedorov, $\neq$ Anton A. Toutov, $\neq$ Nicholas A. Swisher and Robert H. Grubbs*
We report a transition-metal-free protocol for the efficient reductive cleavage of diaryl and aryl alkyl ethers. The combination of triethylsilane with common bases forms an unusually powerful reductive couple that regioselectively ruptures lignin- and coal-related $\mathrm{C}-\mathrm{O}$ bonds in aromatic ethers. Interestingly, with certain bases and temperature regimes ortho-directed $\mathrm{C}-\mathrm{H}$ silylation efficiently competes with the latter process. However, careful tuning of the reactions conditions allows for the selective reductive cleavage of lignin model compounds to their corresponding phenolic and aromatic constituents.
\end{abstract}

Received 17th December 2012

Accepted 17th January 2013

DOI: $10.1039 / c 3 s c 22256 j$

www.rsc.org/chemicalscience

\section{Introduction}

In the past few decades, the growing demand for energy combined with declining fossil fuel reserves has created a tremendous surge in interest for efficient manufacturing of fuels and bulk chemicals from renewable bioresources. ${ }^{1}$ The natural heterobiopolymer lignin has developed into a major target for cost-efficient biomass conversion because the repeating aromatic ether structural units could offer high energy content products and potential access to useful derivatives for fine chemical applications. ${ }^{2}$ However, at present, utilization of lignin is clearly limited since current technology does not allow for efficient decomposition into its constituent building blocks with the desired selectivity. ${ }^{1}$ One of the major challenges associated with such a process is the need to reductively cleave the different types of strong aromatic $\mathrm{C}-\mathrm{O}$ bonds present in lignin, ${ }^{3}$ which is also a relevant problem for the liquefaction of coal (Scheme 1). ${ }^{4}$

Considerable advances in the utilization of aryl alkyl ethers as electrophiles in cross-coupling reactions with $\mathrm{Ni}$ catalysts ${ }^{5}$

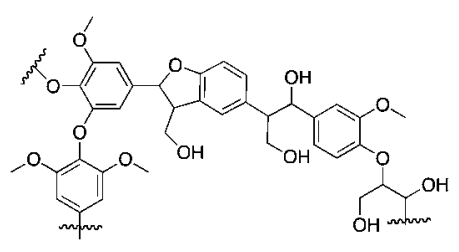

Scheme 1 Examples of $\mathrm{C}-\mathrm{O}$ bonds present in hardwood lignin.

Arnold and Mabel Beckman Laboratories of Chemical Synthesis, Division of Chemistry and Chemical Engineering, California Institute of Technology, Pasadena, California, 91125, USA. E-mail: rhg@caltech.edu; Fax: +1 626-564-9297

$\dagger$ Electronic supplementary information (ESI) available: Full experimental details and NMR spectra. See DOI: $10.1039 / \mathrm{c} 3 s c 22256 \mathrm{j}$

$\ddagger$ These authors contributed equally. has prompted important recent discoveries of selective reductive deoxygenation transformations involving aryl-oxygen bonds. Specifically, Martin has utilized in situ prepared phosphine-ligated Ni species to cleave the aryl-oxygen bond in aryl alkyl ethers using tertiary silanes as the stoichiometric reductant, ${ }^{6}$ and a similar approach was also reported by Chatani. ${ }^{7}$ Switching to $N$-heterocyclic carbenes as supporting ligands for $\mathrm{Ni}$ allowed Hartwig to selectively cleave diaryl ethers with different reductants including dihydrogen and $\mathrm{Et}_{3} \mathrm{SiH}$, albeit with Ni loadings as high as $5-20 \% .^{8-11}$ In a recent contribution by the same group, high catalyst loadings were avoided by employing a heterogeneous Ni catalyst. ${ }^{12}$ Furthermore, Lercher and Zhao demonstrated that the use of silica-supported $\mathrm{Ni}$ nanoparticles allows for efficient cleavage of aryl ethers with dihydrogen in the aqueous phase. ${ }^{13}$ It would be beneficial to have a general methodology for aromatic $\mathrm{C}-\mathrm{O}$ bond cleavage that does not employ nickel ${ }^{14}$ or other transition metal catalysts. The only known alternative approaches for metal free ether cleavage at relatively low temperatures ${ }^{2 a}$ rely on excess alkali metals or electrocatalytic processes ${ }^{15}$ that tend to be costly, unsustainable and impractical. In an attempt to overcome these constraints, we have discovered that in the absence of exogenous transition metal species, stoichiometric mixtures of alkoxide or hydride bases with organosilanes form potent regioselective reductive systems for the cleavage of diaryl and aryl alkyl ethers to the corresponding phenolic and aromatic compounds. Clearly, any practical process of lignin conversion cannot rely on high organosilane loadings and must utilize commercially viable reducing agents such as $\mathrm{H}_{2}$ or methane. Our approach represents a starting point and serves as a guide for further development of useful methods to obtain aromatic feedstocks from biopolymeric materials. Additionally, the directed ortho-silylation that was discovered in conjunction with the ether cleavage studies presented herein holds promise for selective and practical introduction of the silyl group into aromatic frameworks for their subsequent functionalization. 


\section{Results and discussion}

Our investigation into silane-mediated, aromatic $\mathrm{C}-\mathrm{O}$ bond reduction began with dibenzofuran (1) - a model compound for the $\beta-5$ linkage in lignin. ${ }^{1 b}$ A survey of potential reductants identified that the combination of potassium tert-butoxide, triethylsilane and various transition metal complexes forms a potent and convenient system for the reduction of $\mathrm{C}_{\mathrm{ar}}-\mathrm{O}$ bonds.

However, when we performed control experiments in the absence of transition metal species, we observed nearly complete conversion of dibenzofuran. ICP-MS analysis of the reaction mixtures, reactants, and products demonstrated that trace amounts of transition metals did not exceed 10 ppm. ${ }^{16}$ Thus, heating of 1 with 5 equiv. of $\mathrm{Et}_{3} \mathrm{SiH}$ and 2 equiv. of $\mathrm{KO} t$-Bu in a sealed vial in toluene at $100{ }^{\circ} \mathrm{C}$ for 20 hours gave $98 \%$ conversion of dibenzofuran to a mixture of products including the desired $\mathrm{C}_{\mathrm{ar}}-\mathrm{O}$ cleavage product biphenyl-2-ol $(2,38 \%)$ along with five unexpected silylated products (2-7, Table 1, Entry 1). We speculate that under the reaction conditions, 1 is selectively ortho-silylated giving dibenzofurans 3 and $\mathbf{4}$, which in turn undergo $\mathrm{C}-\mathrm{O}$ bond cleavage to biphenyl-2-ols 5-7. Furthermore, reactions in toluene and mesitylene (vide infra) do give solvent-derived silylated products and in the case of toluene where aromatic regioisomers arise, benzylic $\mathrm{C}-\mathrm{H}$ silylation prevails. ${ }^{16}$ Such reactivity with unactivated substrates is particularly remarkable since transition metals and directing groups ${ }^{\mathbf{1 7}}$ or very high temperatures ${ }^{18}$ are normally required for related functionalizations. While this transition-metal-free $\mathrm{C}-\mathrm{H}$ silylation process has potential applications in organic synthesis ${ }^{19}$ and is itself poised for further investigation, we first focused on tuning the selectivity to favour the intended $\mathrm{C}-\mathrm{O}$ scission. Increasing the amount of base to 5 equivalents resulted in improved $63 \%$ yield of 2 at the expense of other products (Entry 2). Switching to $165{ }^{\circ} \mathrm{C}$ in mesitylene while keeping equimolar silane-to-base ratio not only allowed for reduced $\mathrm{Et}_{3} \mathrm{SiH}$ loading, but also cleanly gave targeted biphenyl-2-ol 2 with $85 \%$ yield (Entry 3 ).

Bases other than $\mathrm{KO}$ - $\mathrm{Bu}$ were found to give comparable activity and selectivity for $\mathrm{C}-\mathrm{O}$ bond cleavage. Thus, at $165{ }^{\circ} \mathrm{C}$ potassium ethoxide is somewhat less effective than $\mathrm{KO} t-\mathrm{Bu}$ (Entry 4), while a cesium alkoxide (Entry 5) gave similar selectivity for the formation of desired 2 when compared to potassium tert-butoxide, albeit at lower yield of the reduced product under identical conditions. Given the latter result, it is interesting to note that $\mathrm{Et}_{3} \mathrm{SiH}$ with lithium or sodium tert-butoxide provides no conversion of 1 suggesting that the counter ion plays a critical role in the generation of the active reductant species and, possibly, in activation of the substrate ether. ${ }^{20}$ In order to test this hypothesis we conducted the same reaction with $\mathrm{KO} t$-Bu but in the presence of 18-crown- 6 as a potassium chelator and indeed observed no conversion. ${ }^{16}$ Additionally, our reaction mixtures were EPR active, which is consistent with reactive radicals ${ }^{21}$ that have been documented for homolytic aromatic substitution reactions. ${ }^{22}$ Since it was reported that addition of 1,10-phenanthroline in conjunction with $\mathrm{KO} t-\mathrm{Bu}$ proved beneficial for those processes, ${ }^{22}$ we evaluated its effect and found it to be detrimental since no conversion of 1 was observed.$^{16}$ Based on these initial observations, we propose that the active reductant silicon species may be organosilicates. ${ }^{23-25}$ In order to test for this possibility, we investigated other hydride donors as possible activators for conversion of $\mathbf{1}$. Interestingly, upon switching to $\mathrm{KH}$ in dioxane we obtained monosilylated 3 in excellent selectivity, albeit with diminished conversion, and with no solvent-derived reduced products. This silylation manifold also dominates when sub-stoichiometric amounts of $\mathrm{KO} t$-Bu are used or when the reaction temperature is lowered, as presented in entries 7 and 8 (Table 1). Since GC headspace analysis of sealed reaction mixtures indicated formation of $\mathrm{H}_{2}$, we conducted the reaction opened to an atmosphere of argon

Table 1 Optimization of reductive cleavage of dibenzofuran ${ }^{a, b}$
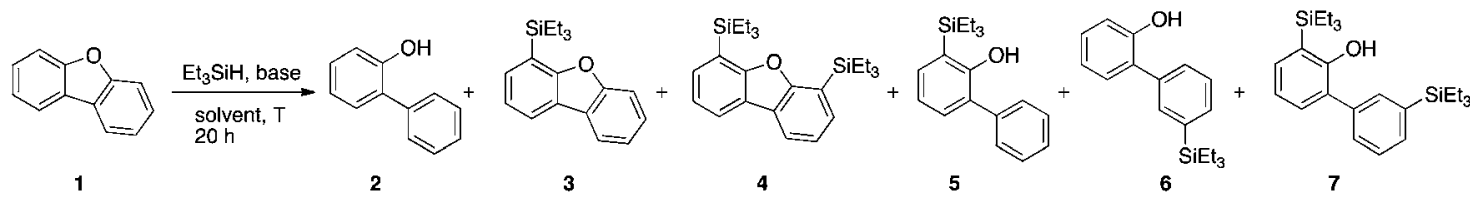

3

4 6

7

\begin{tabular}{|c|c|c|c|c|c|c|c|c|c|c|c|}
\hline Entry & {$[\mathrm{H}]^{c}$ (equiv.) } & Base (equiv.) & Solvent & $T,{ }^{\circ} \mathrm{C}$ & Conv. (\%) & 2 & 3 & 4 & 5 & 6 & 7 \\
\hline 1 & 5 & $\mathrm{KO} t$-Bu (2) & Toluene & 100 & 98 & 38 & 16 & 10 & 21 & 2 & 7 \\
\hline 2 & 5 & $\mathrm{KO} t$-Bu (5) & Toluene & 100 & 97 & 63 & 10 & 2 & 20 & - & 2 \\
\hline 3 & 3 & $\mathrm{KO} t-\mathrm{Bu}(3)$ & Mesitylene & 165 & 100 & $85^{d}$ & 3 & - & 5 & 2 & - \\
\hline 4 & 3 & KOEt (3) & Mesitylene & 165 & 95 & 77 & 10 & - & 6 & 1 & - \\
\hline 5 & 5 & $\mathrm{CsOR}^{e}(3)$ & Toluene & 100 & 89 & 75 & 3 & 11 & - & - & - \\
\hline 6 & 5 & $\mathrm{KH}(1)$ & Dioxane & 100 & 49 & 1 & 43 & 5 & - & - & - \\
\hline 7 & 5 & $\mathrm{KO} t-\mathrm{Bu}(0.5)$ & Toluene & 100 & 90 & 12 & 48 & 20 & 9 & - & 1 \\
\hline 8 & 5 & $\mathrm{KO} t-\mathrm{Bu}(2)$ & Toluene & 80 & 98 & 29 & 18 & 26 & 9 & - & 7 \\
\hline 9 & 5 & $\mathrm{KO} t-\mathrm{Bu}(2)$ & Toluene ${ }^{f}$ & 100 & 98 & 5 & 28 & 46 & - & - & - \\
\hline 10 & 3 & $\mathrm{KO} t-\mathrm{Bu}(3)$ & Mesitylene $e^{g}$ & 165 & 100 & 95 & - & - & - & - & - \\
\hline
\end{tabular}

${ }^{a} \mathrm{GC}$ yields and conversions are reported using tridecane as a standard. ${ }^{b}$ No conversion is observed using base alone or Et $\mathrm{SiH}_{3}$ without basic activators. ${ }^{16}{ }^{c}[\mathrm{H}]=\mathrm{Et}_{3} \mathrm{SiH} .{ }^{d}$ Isolated yield of 2 was $79 \% .{ }^{e} \mathrm{R}=2$-ethylhexyl. ${ }^{f}$ Reaction conducted open to an Ar line. ${ }^{g}$ With 1,4 -cyclohexadiene (100 equiv.) as a co-solvent. 
and found a dramatic decrease in reductive cleavage product formation that was offset by increased silylation (Entry 9). This result suggests that dihydrogen might be important to prevent decomposition of the active reducing species. ${ }^{26}$ In a search to further modulate the selectivity by shutting down radical pathways we conducted the reaction using 1,4-cyclohexadiene as a non-polar hydrogen donor ${ }^{27}$ co-solvent and observed exclusive formation of 2 with 95\% yield (Entry 10). These results demonstrate our ability to tune the selectivity of the reaction by optimizing the reaction conditions.

In order to explore the cleavage of aryl ether $\mathrm{C}-\mathrm{O}$ bonds in unstrained substrates and probe if it proceeds without undesired overreduction of the resulting aromatic fragments, we subjected diphenyl ether to the additives-free optimized reaction conditions described above. This substrate provided benzene and phenol in moderate yields (Table 2, Entry 1) with the rest of the mass balance being attributed principally to silylated as well as other unidentified products. With this result in hand we proceeded to evaluate the reactivity of more complex diaryl ethers. Both symmetrical and unsymmetrical diaryl ethers were shown to be competent substrates and underwent C-O cleavage with good to excellent efficiencies (Entries 2-7). Many of the evaluated diaryl ethers proved more reactive as compared to diphenyl ether and allowed for the use of milder reaction conditions. In the case of 1-naphthyl phenyl ether (Entry 5), bond cleavage occurred regiospecifically at the naphthyl $\mathrm{C}-\mathrm{O}$ bond to furnish naphthalene and phenol in 70

Table 2 Reductive cleavage of diaryl ethers ${ }^{a}$

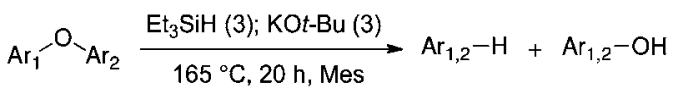

\begin{tabular}{|c|c|c|c|c|}
\hline & & & $\mathrm{Ar}_{1}-\mathrm{H}$ & $\mathrm{Ar}_{1}-\mathrm{OH}$ \\
\hline Entry & Diaryl ether & Conv. (\%) & $\mathrm{Ar}_{2}-\mathrm{H}$ & $\mathrm{Ar}_{2}-\mathrm{OH}$ \\
\hline
\end{tabular}

1

2

3

$4^{b}$

$5^{c}$

$6^{d}$

$7^{d}$
96

100<smiles>CC(C)(C)c1ccc(Oc2ccc(C(Br)(Br)c3ccccc3)cc2)cc1</smiles><smiles>Cc1ccc(Oc2ccc([N+](=O)[O-])cc2)cc1</smiles>

100

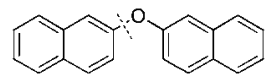

100

$\mathrm{Ar}_{1}-\mathrm{Ar}_{2} \quad \begin{aligned} & \mathrm{Ar}_{1}=\text { phenyl } \\ & \mathrm{Ar}_{2}=1 \text {-naphthyl }\end{aligned}$

$\mathrm{Ar}_{1} \mathrm{O}_{1} \mathrm{Ar}_{2} \mathrm{Ar}_{1}=2$-naphthyl
$\mathrm{Ar}_{2}=1$-naphthyl

100

100

100
64

76

52

50

$-$

70

57

41

19

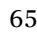

98

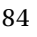

88

91

-

58

15

21

65
${ }^{a}$ GC yields and conversions are reported using tridecane as a standard.

${ }^{b}$ Trace amount of 1,2,3,4-tetrahydronaphthalene was detected.

${ }^{c}$ Reaction was run at $100{ }^{\circ} \mathrm{C}$ for $20 \mathrm{~h}$ in toluene with 2 equiv. each of

$\mathrm{Et}_{3} \mathrm{SiH}$ and $\mathrm{KO}$-Bu. ${ }^{d}$ Reaction was run at $75{ }^{\circ} \mathrm{C}$ for $40 \mathrm{~h}$ in toluene. and $91 \%$ yield respectively, with no 1-naphthol or benzene detected. With the unsymmetrical dinaphthyl ether (Entry 5), $\mathrm{C}-\mathrm{O}$ bond reduction occurred regioselectively to provide 2-naphthol and 1-naphthol in good combined yield with approximately a $4: 1$ ratio of the two isomers, respectively. The unsymmetrical para-phenyl substituted diphenyl ether (Entry 7) reacts with good overall yield and with moderate regioselectivity for reduction of the slightly more electron rich $\mathrm{C}-\mathrm{O}$ bond $^{28}$ indicating the apparent influence of electronic effects in siteselectivity of $\mathrm{C}-\mathrm{O}$ bond cleavage. This factor becomes determining for the selectivity of cleavage of 4-O-5 lignin models that contain strong methoxy donors adjacent to the $\mathrm{C}-\mathrm{O}$ bond being broken (vide infra, Scheme 3). We also wish to point out that such selectivity is complementary to that reported by Hartwig for homogeneous $\mathrm{Ni}$ catalyzed reduction with dihydrogen wherein unsymmetrical diaryl ethers were preferentially cleaved at the side of the more electron-deficient aryl ring. ${ }^{8}$

We next investigated the reduction of aryl alkyl ethers under the optimized conditions applied to diaryl ethers to probe the cleavage selectivity of $\mathrm{sp}^{2}$ versus $\mathrm{sp}^{3} \mathrm{C}-\mathrm{O}$ bond. ${ }^{29}$ The reaction of 2-methoxynaphthalene gave 2-naphthol as the major product in moderate yield (Scheme 1). GC-MS analysis of the crude reaction mixture indicated the presence of trace amounts of naphthalene along with 2-methylnaphthalene and further reduced species, including products of partial aromatic reduction. Compounds presumably derived from 2-naphthol silylation were also detected. ${ }^{\mathbf{1 6}}$ Likewise, cleavage of 2-ethoxynapthalene under the same conditions gave 2-naphthol in slightly higher yield, but with the same or analogous side products. We next chose to investigate sterically bulkier ethers to probe the versatility and possible mechanism of the $\mathrm{C}-\mathrm{O}$ bond cleavage. Despite the large alkyl substituent adjacent to the ether oxygen, reaction of 2-neopentyloxynaphthalene provided 2-naphthol in approximately the same yield as with the less bulky substrates. Even 2-tert-butyloxynapthalene was cleaved to give the expected naphthol in 55\% yield (Scheme 2). Control experiments performed at identical conditions but without triethylsilane provided 2-naphthol in cases of 2-ethoxy- and 2-tert-butyloxynapthalene albeit with substantially diminished yields. Since 2-methoxy- and 2-neopentyloxy-substrates remained intact in such silane-free cleavages, a $\beta$ elimination mechanism is likely to be operative. ${ }^{30}$

When we attempted to reduce 4-tert-butyl and 4-methyl anisoles under the standard conditions, the yields of the corresponding phenols were high, likely because of more challenging silylation of the substituted phenyl ring for the steric reasons (Scheme 2). Overall, the selectivity for alkyl C-O bond

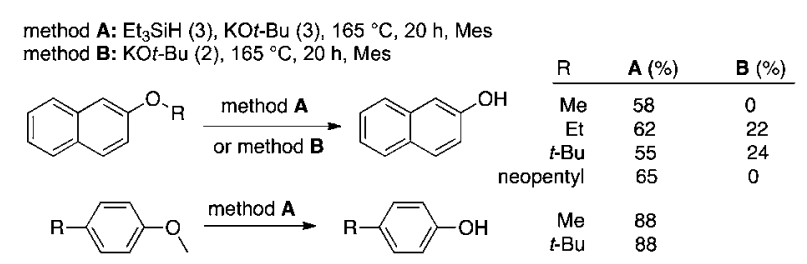

Scheme 2 Reductive cleavage of aryl alkyl ethers. 
method A: $\mathrm{Et}_{3} \mathrm{SiH}(5), \mathrm{KOt}$-Bu (2), $100^{\circ} \mathrm{C}, 20 \mathrm{~h}$, toluene; method B: $\mathrm{Et}_{3} \mathrm{SiH}(3), \mathrm{KOt}-\mathrm{Bu}(3), 165^{\circ} \mathrm{C}, 20 \mathrm{~h}$, mesitylene
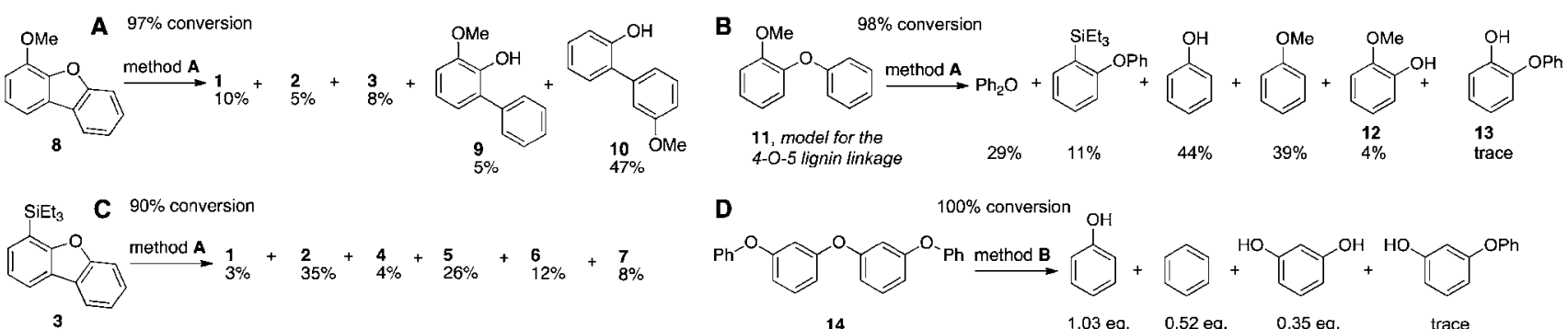

$1.03 \mathrm{eq}$.

0.52 eq. $\quad 0.35 \mathrm{eq}$.

trace

Scheme 3 Reductive cleavages of lignin model substrates and 4-(triethylsilyl)dibenzofuran.

scission contrasts with that observed in $\mathrm{Ni}^{-6-8}$ and borane ${ }^{26}$ catalyzed $\mathrm{C}-\mathrm{O}$ cleavage reactions where aryl $\mathrm{C}-\mathrm{O}$ reduction occurs. It is also notable that under our conditions only trace amounts of naphthalene ring hydrogenation products were observed, which contrasts with the results of silane-based ionic hydrogenations reported in the literature. ${ }^{31}$

It is instructive to compare the cleavages of methoxysubstituted diaryl ethers $\mathbf{8}$ and $\mathbf{1 1}$ (Scheme 3) with the results presented above. While aryl alkyl ethers show strong preference for the reduction of alkyl oxygen over aryl oxygen bonds, both methoxy substrates in Scheme 3 demonstrate a reversal of regioselectivity, furnishing almost exclusively aryl oxygen bond rupture products. We attribute this effect to the presence of a donor oxygen atom ortho to the $\mathrm{C}-\mathrm{O}$ bond undergoing rupture. Supporting this inference is the high selectivity of the reductive ring-opening of dibenzofuran derivative $\mathbf{8}$ that mainly leads to 10. Likewise, preferred formation of phenol and anisole is observed with similar selectivity over phenols $\mathbf{1 2}$ and $\mathbf{1 3}$ in the cleavage of lignin model 11. We speculate that such an effect can be rationalized by the oxygen atom resonance stabilization of the positive charge build up during electrophilic activation of the $\mathrm{C}-\mathrm{O}$ bond that is being broken. In order to test this hypothesis, we subjected 3 to our reaction conditions and isolated the ringopened phenols $\mathbf{5}$ and $\mathbf{6}$ along with the desilylated products $\mathbf{1}$ and 2 (Scheme 3, inset C). In the absence of resonance stabilization, the selectivity of cleavage was reversed in favour of isomer $\mathbf{5}$. It is also worth noting that, as formation of $\mathbf{1}$ and $\mathbf{2}$ demonstrates, the silylation reaction is thus reversible under the typical reaction conditions. ${ }^{32}$ After having illustrated the potential for the challenging 4-O-5 lignin models 8 and 11, we decided to examine our method with an oligomeric ether 14 that contains six $\mathrm{C}_{\mathrm{ar}}-\mathrm{O}$ bonds (Scheme 3, inset D). Remarkably, at $165^{\circ} \mathrm{C}$ in mesitylene quantitative conversion of $\mathbf{1 4}$ was achieved and gave phenol, benzene, resorcinol and other unidentified products with merely 0.5 equiv. of silane per aryl oxygen bond.

Comprehensive mechanistic studies are required before the underlying reaction pathways can be reliably established. However, having observed no conversion of 3 under basic conditions and smooth reductive cleavage of 4,6-dimethyldibenzofuran 15 into the corresponding biphenyl-2-ol 16 (Scheme 4), one can rule out intermediacy of benzynes, as the presence of ortho-silylated aromatic ethers might have initially suggested. Very little deuterium incorporation into 2 occurs

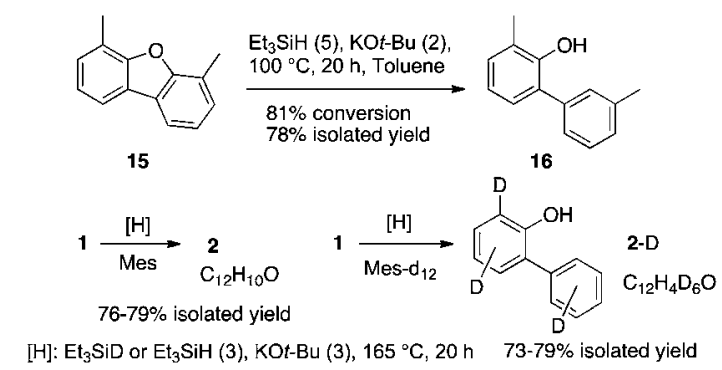

Scheme 4 Reductive cleavage of 4,4'-dimethyldibenzofuran and deuterium incorporation experiments.

when dibenzofuran is reacted with $\mathrm{Et}_{3} \mathrm{SiD}$ in mesitylene at $165^{\circ} \mathrm{C}$ (Scheme 4). In line with this, identical base peaks in high-resolution MS spectra of biphenyl-2-ol prepared either from $\mathrm{Et}_{3} \mathrm{SiH}$ or $\mathrm{Et}_{3} \mathrm{SiD}$ in $\mathrm{Mes}^{-\mathrm{d}_{12}}$ indicate that rapid $\mathrm{H} / \mathrm{D}$ exchange with the solvent occurs under the reaction conditions. Interestingly, as proton, carbon and HSQC spectra of deuterated 2 suggest, while all of the protons undergo partial H/D exchange, only for the ortho- $\mathrm{OH}$ position this process reaches completion.

As mentioned previously, it appears probable that alkyl organosilicates are the key reactive species involved..$^{33,34}$ To the best of our knowledge no known variants of organosilicates have been reported to possess such powerful reducing properties that can affect the reductive ruptures described in this work. $^{35}$

\section{Conclusions}

In summary, we have described a novel protocol for the reduction of recalcitrant aryl ether $\mathrm{C}-\mathrm{O}$ bonds, which constitutes an important advance towards the goal of lignin conversion. Remarkably, this challenging transformation occurs by action of simple, commercially available reagents that operate in the absence of exogenous transition-metal species. Our protocol is regioselective, easily tunable and is not accompanied by hydrogenation of aromatic rings in appreciable amounts.

\section{Acknowledgements}

Support of this work from $\mathrm{BP}$ under the $\mathrm{XC}^{2}$ program is gratefully acknowledged. A.A.T. is grateful to NSERC for a PGS D 
fellowship. A. F. thanks Dr Erik P. A. Couzijn (ETH Zürich) for helpful discussions.

\section{Notes and references}

1 (a) J. C. Hicks, J. Phys. Chem. Lett., 2011, 2, 2280; (b) J. Zakzeski, P. C. A. Bruijnincx, A. L. Jongerius and B. M. Weckhuysen, Chem. Rev., 2010, 110, 3552; (c) J. R. Regalbuto, Science, 2009, 325, 822; (d) G. W. Huber, S. Iborra and A. Corma, Chem. Rev., 2006, 106, 4044.

2 For selected recent advances, see: $(a)$ V. M. Roberts, V. Stein, T. Reiner, A. Lemonidou, X. Li and J. A. Lercher, Chem.-Eur. J., 2011, 17, 5939; (b) T. D. Matson, K. Barta, A. V. Iretskii and P. C. Ford, J. Am. Chem. Soc., 2011, 133, 14090; (c) K. Barta, T. D. Matson, M. L. Fettig, S. L. Scott, A. V. Iretskii and P. C. Ford, Green Chem., 2010, 12, 1640; (d) M. Kleinert and T. Barth, Energy Fuels, 2008, 22, 1371; (e) T. H. Parsell, B. C. Owen, I. Klein, T. M. Jarrell, C. L. Marcum, L. J. Haupert, L. M. Amundson, H. I. Kenttämaa, F. Ribeiro, J. T. Miller and M. M. Abu-Omar, Chem. Sci., 2013, 4, 806.

3 (a) R. Parthasarathi, R. A. Romero, A. Redondo and S. Gnanakaran, J. Phys. Chem. Lett., 2011, 2, 2660; (b) S. Kim, S. C. Chmely, M. R. Nimlos, Y. J. Bomble, T. D. Foust, R. S. Paton and G. T. Beckham, J. Phys. Chem. Lett., 2011, 2, 2846.

4 D. G. Levine, R. H. Schlosberg and B. G. Silbernagel, Proc. Natl. Acad. Sci. U. S. A., 1982, 79, 3365.

5 (a) B. M. Rosen, K. W. Quasdorf, D. A. Wilson, N. Zhang, A.-M. Resmerita, N. K. Garg and V. Percec, Chem. Rev., 2011, 111, 1346; (b) D.-G. Yu, B.-J. Li and Z.-J. Shi, Acc. Chem. Res., 2010, 43, 1486; (c) M. Tobisu and N. Chatani, Top. Organomet. Chem., 2013, 44, 35; (d) B.-J. Li, D.-G. Yu, C.-L. Sun and Z.-J. Shi, Chem.-Eur. J., 2011, 17, 1728.

6 P. Álvarez-Bercedo and R. Martin, J. Am. Chem. Soc., 2010, 132, 17352.

7 M. Tobisu, K. Yamakawa, T. Shimasaki and N. Chatani, Chem. Commun., 2011, 47, 2946.

8 A. G. Sergeev and J. F. Hartwig, Science, 2011, 332, 439, also see ESI $\dagger$ to this article.

9 Mechanistic details about Ni-catalyzed aryl-oxygen cleavage were recently reported: P. Kelley, S. Lin, G. Edouard, M. W. Day and T. Agapie, J. Am. Chem. Soc., 2012, 134, 5480.

10 For examples of other transition metal catalyzed approaches to breaking lignin-related $\mathrm{C}-\mathrm{O}$ bonds, see: (a) B. Sedai, C. Díaz-Urrutia, R. T. Baker, R. Wu, L. A. P. Silks and S. K. Hanson, ACS Catal., 2011, 1, 794; (b) J. M. Nichols, L. M. Bishop, R. G. Bergman and J. A. Ellman, J. Am. Chem. Soc., 2010, 132, 12554; (c) S. Son and F. D. Toste, Angew. Chem., Int. Ed., 2010, 49, 3791; (d) S. K. Hanson, R. T. Baker, J. C. Gordon, B. L. Scott and D. L. Thorn, Inorg. Chem., 2010, 49, 5611; (e) C. Crestini, M. Crucianelli, M. Orlandi and R. Saladino, Catal. Today, 2010, 156, 8; (f) M. S. Kharasch and R. L. Huang, J. Org. Chem., 1952, 17, 669. 11 For Ir-based cleavage of alkyl ethers with $\mathrm{Et}_{3} \mathrm{SiH}$, see: J. Yang, P. S. White and M. Brookhart, J. Am. Chem. Soc., 2008, 130, 17509.
12 A. G. Sergeev, J. D. Webb and J. F. Hartwig, J. Am. Chem. Soc., 2012, 134, 20226.

13 J. He, C. Zhao and J. A. Lercher, J. Am. Chem. Soc., 2012, 134, 20768.

14 Allergic reactions caused by nickel were recently reviewed: R. Darlenski, J. Kazandjieva and K. Pramatarov, Int. J. Dermatol., 2012, 51, 523.

15 (a) Z. Grobelny, Eur. J. Org. Chem., 2004, 2973; (b) A. Maercker, Angew. Chem., Int. Ed. Engl., 1987, 26, 972; (c) T. Keumi, C. Murata, Y. Sasaki and H. Kitajima, Synthesis, 1980, 634.

16 See ESI $\dagger$ for details.

17 F. Kakiuchi, K. Tsuchiya, M. Matsumoto, E. Mizushima and N. Chatani, J. Am. Chem. Soc., 2004, 126, 12792.

18 N. Tsukada and J. F. Hartwig, J. Am. Chem. Soc., 2005, 127, 5022.

19 L. T. Ball, G. C. Lloyd-Jones and C. A. Russell, Science, 2012, 337, 1644.

20 Corriu reported that in contrast to potassium, sodium or lithium alkoxides do not give hydridosilicates with trialkoxy or triaryloxysilanes: B. Becker, R. Corriu, C. Guerin and Q. Wang, J. Organomet. Chem., 1989, 359, C33.

21 Radical silylation of arenes is well known. See, for example: (a) W. Du, B. Kaskar, P. Blumbergs, P.-K. Subramanian and D. P. Curran, Bioorg. Med. Chem., 2003, 11, 451; (b) C. Chatgilialoglu, Chem. Rev., 1995, 95, 1229.

22 (a) C.-L. Sun, H. Li, D.-G. Yu, M. Yu, X. Zhou, X.-Y. Lu, K. Huang, S.-F. Zheng, B.-J. Li and Z.-J. Shi, Nat. Chem., 2010, 2, 1044, also see ESI $\dagger$ to this article; $(b)$ A. Studer and D. P. Curran, Angew. Chem., Int. Ed., 2011, 50, 5018.

23 (a) R. Holmes, Chem. Rev., 1996, 96, 927; (b) C. Chuit, R. J. P. Corriu, C. Reye and J. C. Young, Chem. Rev., 1993, 93, 1371; (c) S. E. Denmark and G. L. Beutner, Angew. Chem., Int. Ed., 2008, 47, 1560; (d) E. P. A. Couzijn, J. C. Slootweg, A. W. Ehlers and K. Lammertsma, Z. Anorg. Allg. Chem., 2009, 635, 1273.

24 (a) P. D. Prince, M. J. Bearpark, G. S. McGrady and J. W. Steed, Dalton Trans., 2008, 271; (b) M. J. Bearpark, G. S. McGrady, P. D. Prince and J. W. Steed, J. Am. Chem. Soc., 2001, 123, 7736; (c) N. Rot, T. Nijbacker, R. Kroon, F. J. J. de Kanter, F. Bickelhaupt, M. Lutz and A. L. Spek, Organometallics, 2000, 19, 1319; (d) R. Corriu, C. Guerin, B. Henner and Q. Wang, Inorg. Chim. Acta, 1992, 198-200, 705; (e) R. J. P. Corriu, C. Guerin, B. J. L. Henner and Q. Wang, Organometallics, 1991, 10, 3574; $(f)$ R. J. P. Corriu, C. Guerin, B. Henner and Q. Wang, Organometallics, 1991, 10, 2297; (g) R. J. P. Corriu, C. Guerin, B. J. L. Henner and Q. Wang, J. Organomet. Chem., 1992, 439, C1.

25 (a) D. J. Hajdaszj, Y. Ho and R. R. Squires, J. Am. Chem. Soc., 1994, 116, 10751; (b) I. H. Krouse and P. G. Wenthold, Organometallics, 2004, 23, 2573, and references therein.

26 Hydrogenolysis of arenes and alkyl aryl ethers with $\mathrm{H}_{2}$ under borane catalysis is precedented: M. Yalpani, T. Lunow and R. Koester, Chem. Ber., 1989, 122, 687.

27 A. L. Koner, U. Pischel and W. M. Nau, Org. Lett., 2007, 9, 2899. 
28 The Hammett parameters for $p$-Ph substituents are -0.18 for $\sigma^{+}$series and -0.01 for $\sigma$, see: C. Hansch, A. Leo and R. W. Taft, Chem. Rev., 1991, 91, 165.

29 For alkyl aryl cleavage under Lewis acid catalysis, see: V. Gevorgyan, J.-X. Liu, M. Rubin, S. Benson and Y. Yamamoto, Tetrahedron Lett., 1999, 40, 8919.

30 R. L. Letsinger and D. F. Pollart, J. Am. Chem. Soc., 1956, 78, 6079, also see ref. $15 \mathrm{~b}$

31 (a) J. W. Larsen and L. W. Chang, J. Org. Chem., 1979, 44, 1168; (b) M. Eckert-Maksić and D. Margetić, Energy Fuels, 1993, 7, 315.

32 We checked if the qualitative $\mathbf{5 / 6}$ ratio depends on the desilylation rate after dibenzofuran ring opening in $\mathbf{3}$ had occurred by subjecting the two isomers independently to the reaction conditions and found that isomer 5 loses the $\mathrm{Et}_{3} \mathrm{Si}$-group faster than $\mathbf{6}$, thus supporting our speculations. 33 GC analysis of a crude reaction mixture obtained after heating of 1 for 20 hours in toluene at $100{ }^{\circ} \mathrm{C}$ with 2 equiv. of an isolated silicate $\mathrm{K}\left[\mathrm{HSi}(\mathrm{OEt})_{4}\right]$ indicates formation of 2 among other products: Grubbs, et al., unpublished results.

34 For electron transfer chemistry of hydridosilicates, see: $(a)$ R. Corriu, C. Guerin, B. Henner and Q. Wang, J. Organomet. Chem., 1989, 365, C7; (b) D. Yang and D. D. Tanner, J. Org. Chem., 1986, 51, 2267.

35 Intermediacy of putative fluoride-activated silicates in the reductions if imides was recently proposed: S. Das, D. Addis, L. R. Knöpke, U. Bentrup, K. Junge, A. Brückner and M. Beller, Angew. Chem., Int. Ed., 2011, 50, 9180. 